\author{
Jurnal E-KOMTEK (Elektro-Komputer-Teknik) \\ Vol. 4, No. 2 (2020) pp. 200-208 \\ https://jurnal.politeknik-kebumen.ac.id/index.php/E-KOMTEK \\ p-ISSN : 2580-3719 e-ISSN : 2622-3066
}

\title{
Pengembangan Media Pembelajaran Sistem Air Conditioner Berbasis Android Sketchware di Politeknik Dharma Patria
}

\author{
Bahtiar Wilantara ${ }^{*}$, Hamid Nasrullah ${ }^{2}$, Akhmad Nurwahid $^{3}$ \\ 1,2,3Mesin Otomotif, Politeknik Dharma Patria, Kebumen, Indonesia, 54311 \\ *E-mail : bahtiar@politeknik-kebumen.ac.id \\ Doi : https://doi.org/10.37339/e-komtek.v4i2.402
}

Diterbitkan oleh Politeknik Dharma Patria Kebumen

Info Artikel
Diterima :
02-12-2020
Diperbaiki :
13-12-2020
Disetujui :
13-12-2020

\begin{abstract}
ABSTRAK
Tujuan penelitian adalah mengembangkan media pembelajaran berbasis android sketchware untuk kompetensi sistem air conditioner di Politeknik Dharma Patria. Metode penelitian adalah penelitian pengembangan (research and development) yang terdiri dari analysis, design, development, implementation, dan evaluation. Penelitian ini dilakukan di Politeknik Dharma Patria Prodi Teknik Mesin Otomotif. Uji produk dilakukan oleh dua ahli materi dan media untuk mengetahui kelayakan, serta pengujian pada pengguna akhir yaitu mahasiswa prodi teknik mesin otomotif. Hasil penelitian: 1) pengembangan media pembelajaran berbasis android terdiri dari delapan komponen, yaitu: sejarah, komponen, kelistrikan, cara kerja, perawatan, soal, dan jobsheet sistem air conditioner. (2) Penilaian kelayakan ahli materi dalam kategori sangat layak dengan skor retata 77. Penilaian kelayakan ahli media dalam kategori sangat layak dengan skor rerata 75. 3) Media pembelajaran berbasis android sketchware untuk kompetensi sistem air conditioner efektif digunakan di Politeknik Dharma Patria.
\end{abstract}

Kata kunci: Media Pembelajaran; Android Sketchware; Sistem Air Conditioner.

\begin{abstract}
The research objective was to develop learning media based on sketchware android for the competence of the air conditioner system at the Dharma Patria Polytechnic. The research method is development research (research and development) which consists of analysis, design, development, implementation, and evaluation. This research was conducted at the Dharma Patria Polytechnic Automotive Mechanical Engineering Study Program. Product testing was carried out by two material and media experts to determine feasibility, as well as testing on the end user, namely students of the automotive mechanical engineering study program. The results of the study: 1) the development of Android-based learning media consists of eight components, namely: history, components, electricity, how to work, maintenance, questions, and the air conditioner system jobsheet. (2) The assessment of the feasibility of material experts in the very feasible category with a random score of 77. The assessment of the feasibility of media experts in the very feasible category with a mean score of 75.3) Android sketchware-based learning media for the competence of the air conditioner system is effectively used at the Dharma Patria Polytechnic.

Keywords: Learning Media,; Android Sketchware; Air Conditioner System.
\end{abstract}

Alamat Korespondensi $\quad: \quad$ Jl. Letnan Jenderal Suprapto No.73 Kebumen, Jawa Tengah, Indonesia 55431 This work is licensed under a Creative Commons Attribution-NonCommercial 4.0 International License. 


\section{PENDAHULUAN}

Mobile learning merupakan cara memanfaatkan telepon seluler sebagai media pembelajaran. Mobile learning menjadi salah satu alternatif pengembangan media pembelajaran [1]. Media pembelajaran berbasis android sangat layak dikembangkan untuk Sekolah Menengah Kejuruan [2]. Dalam mengembangkan smartphone menjadi media pembelajaran mobile learning dengan mempertimbangkan sistem yang digunakan. Sistem operasi menjadi penghubung antara aplikasi dengan hardware pada smartphone sehingga pengguna dapat menjalankan fungsi atau menu tertentu [3].

Penggunaan mobile learning dapat meningkatkan prestasi, motivasi dan membuat proses pembelajaran lebih menarik. Pengembangan mobile learning dapat digunakan sebagai media belajar untuk peserta didik disekolah atau diluar sekolah dan digunakan oleh guru atau dosen sebagai media pembelajaran [4].

Salah satu pengembangan media pembelajaran berbasis aplikasi android yaitu buku saku digital. Pengembangan mobile learning layak dilakukan uji coba dan validitas sebagai media pembelajaran [5]. Pada pengembangan multimedia berbasis android di Sekolah Menengah Kejuruan pada aspek materi dikategorikan layak dan pada aspek media dikategorikan sangat layak untuk kompetensi dasar pengukuran listrik [6].

Salah satu aplikasi yang dapat digunakan sebagai mobile learning adalah aplikas sketchware. Aplikasi mobile learning menggunakan aplikasi sketchware pada SMK Negeri 2 Pangkalpinang memberikan kemudahan guru dalam melakukan proses pengajaran [7]. Pengembangan media pembelajaran menggunakan sketchware layak digunakan sebagai media pembelajaran pada materi good manufacturing practices untuk mengetahui kemampuan literasi visual di SMK PPN Lembang [8].

\section{MATERIAL DAN METODE}

\subsection{Material}

a. Air Conditioner

Air conditioner merupakan perlengkapan untuk memelihara udara didalam ruangan sesuai dengan keinginan pengguna [9]. Air conditioner merupakan alat untuk mengatur udara didalam ruangan supaya temperatur dan kelembabannya sesuai dengan yang dikehendaki [10] Jika didalam ruangan bertempertur rendah, maka panas akan diberikan supaya temperatur naik 
(pemanasan), dan jika temperatur didalam ruangan tinggi, maka panas pada ruangan akan diturunkan (pendinginan).

\section{b. Sketchware}

Sketchware merupakan aplikasi android yang berfungsi untuk membuat aplikasi android. Aplikasi berupa game android, kalkulator, notepad dan lain sebaginya. Sketchware merupakan sebuah blok pemrograman scratch untuk mengembangkan aplikasi android mobile.

Sketchware menggunakan bahasa blok seperti scratch. Scratch merupakan sebuah bahasa pemrograman yang inovatif diciptakan oleh MIT (Massachusetts Institute of Technology) yang mengubah bahasa kompleks coding berbasis teks kedalam blok bangunan visual dragand-drop. Scratch adalah suatu bahasa yang sederhana, bahkan anak-anak kecil dapat belajar mengembangkan.

Sketchware diterjemahkan Scratch ke dalam kode Java dan sumber XML, sehingga tidak ada batasan pada apa yang dapat kembangkan. Sketchware menyediakan tutorial yang dapat ikuti untuk menjadi ahli di blok Scratch pemrograman dan pengembangan aplikasi android. Setiap contoh berisi konsep-konsep pemrograman dapat memahami dengan menyelesaikan proyek.

\section{$2.2 \quad$ Metode}

Penelitian penelitian adalah penelitian Research and Development (R\&D). Model pengembangan media pembelajaran berbasis android sketchware adalah analysis, design, development, implementation, dan evaluation. Penelitian dilakukan di Politeknik Dharma Patria Prodi Studi Teknik Mesin Otomotif. Uji kelayakan produk dilakukan oleh ahli materi dan media, serta uji coba produk akhir yaitu mahasiswa prodi teknik mesin otomotif.

\section{HASIL DAN PEMBAHASAN}

\subsection{Hasil Pengembangan Media Pembelajaran Berbasis Android Sketchware}

Hasil penelitian yaitu pengembangan media pembelajaran berbasis android yang digunakan sebagai media pembelajaran. Aplikasi terdiri dari halaman-halaman yang saling berkaitan menggunakan tampilan menu. Tampilan layar utama disajikan pada Gambar 1. 


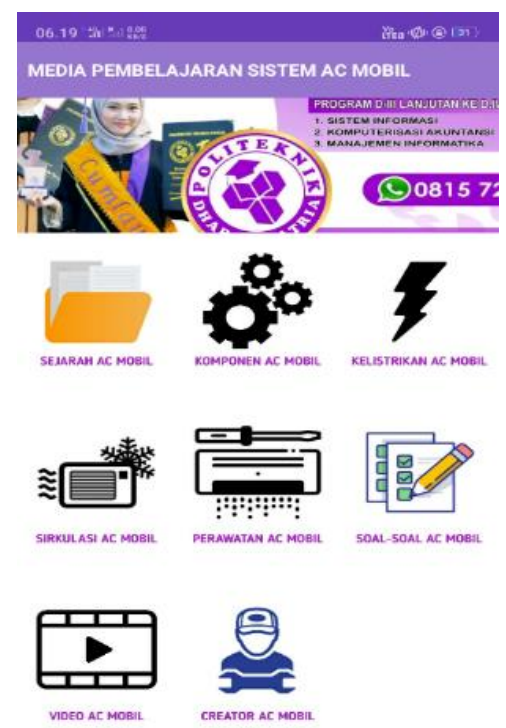

Gambar 1. Tampilan Layar Utama Aplikasi

Layar utama berisi menu untuk mengakses halaman yang diinginkan. Menu pada halaman utama antara lain: sejarah, komponen, kelistrikan, cara kerja, perawatan, soal, dan jobsheet sistem air conditioner. Pada layar sejarah sistem air conditioner berisi tentang sejarah ditemukan air conditioner. Layar sejarah sistem air conditioner disajikan pada Gambar 2.

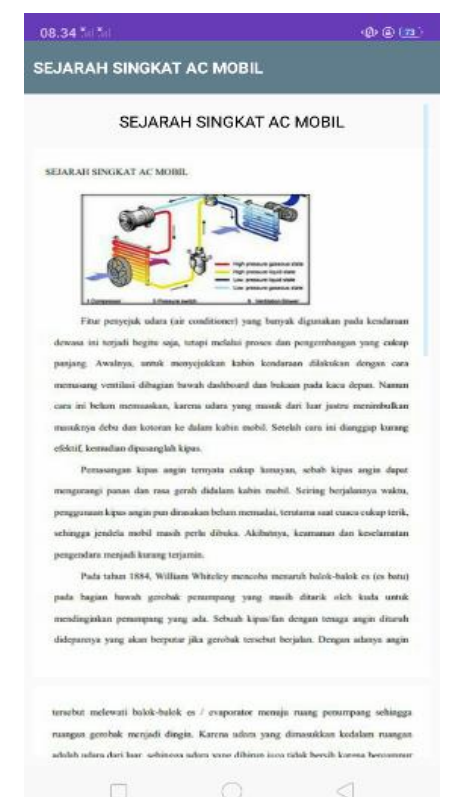

\section{Gambar 2. Tampilan Layar Sejarah Sistem Air Conditioner}

Pada layar komponen sistem air conditioner berisi berisis tentang data-data atau materi tentang komponen pada air conditioner. Layar komponen sistem air conditioner disajikan pada

\section{Gambar 3.}




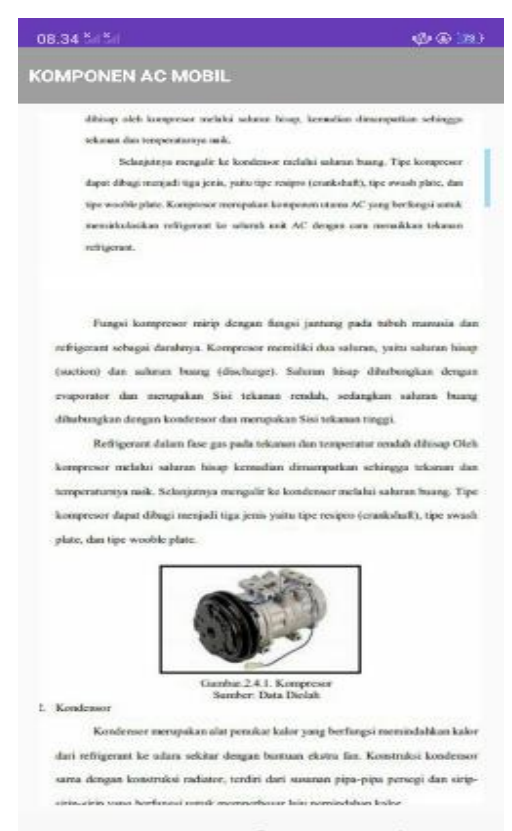

Gambar 3. Tampilan Layar Komponen Sistem Air Conditioner

Pada layar kelistrikan sistem air conditioner berisi berisis tentang data-data atau materi tentang kelistrikan pada air conditioner. Layar kelistrikan sistem air conditioner disajikan pada

\section{Gambar 4.}

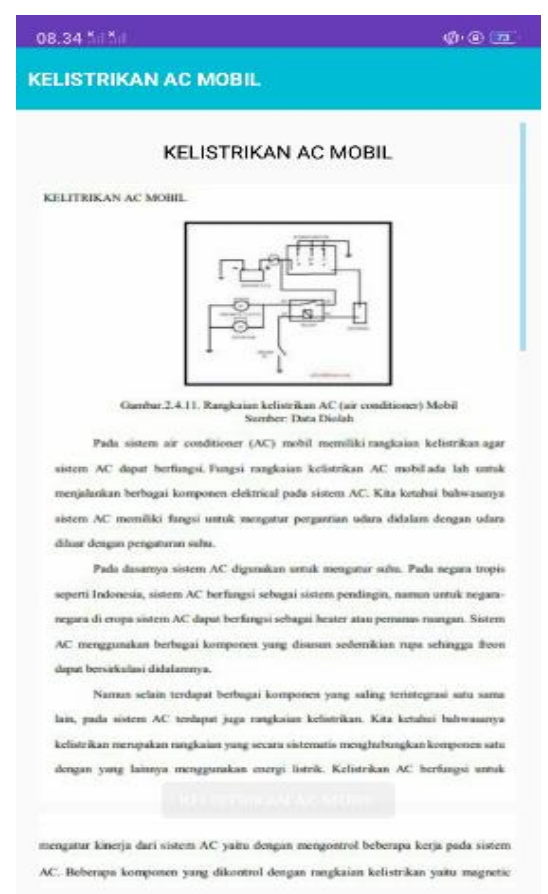

Gambar 4. Tampilan Layar Kelistrikan Sistem Air Conditioner

Pada layar cara kerja sistem air conditioner berisi berisis tentang data-data atau materi tentang cara kerja pada air conditioner. Layar cara kerja sistem air conditioner disajikan pada Gambar 5. 


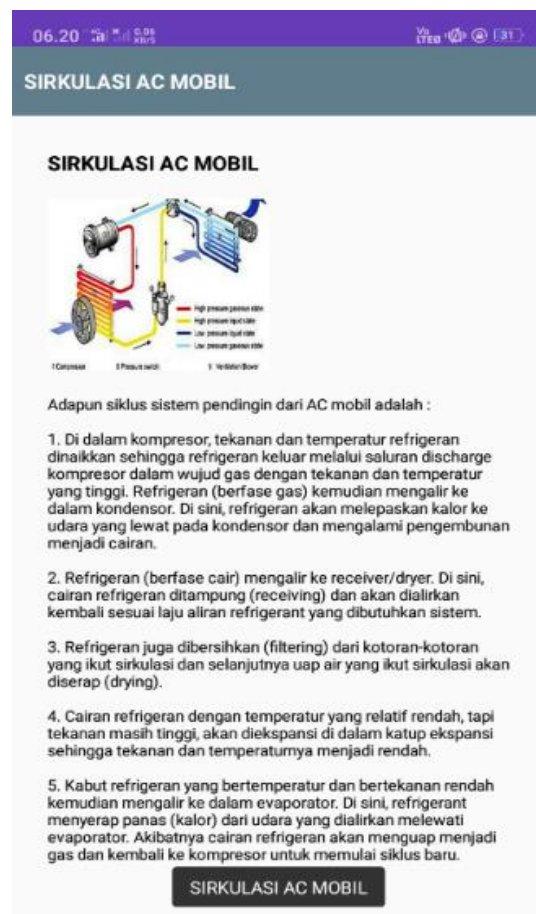

Gambar 5. Tampilan Layar Cara Kerja Sistem Air Conditioner

Pada layar perawatan sistem air conditioner berisi berisis tentang data-data atau materi tentang perawatan pada air conditioner. Layar perawatan sistem air conditioner disajikan pada

\section{Gambar 6.}

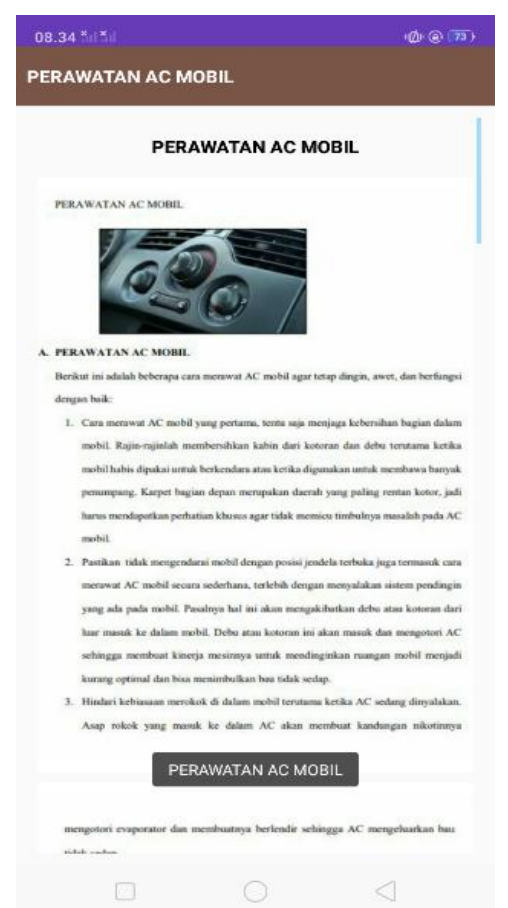

Gambar 6. Tampilan Layar Perawatan Sistem Air Conditioner 
Pada layar soal sistem air conditioner berisi berisis tentang data-data atau materi tentang perawatan pada air conditioner. Layar soal sistem air conditioner disajikan pada Gambar 7.

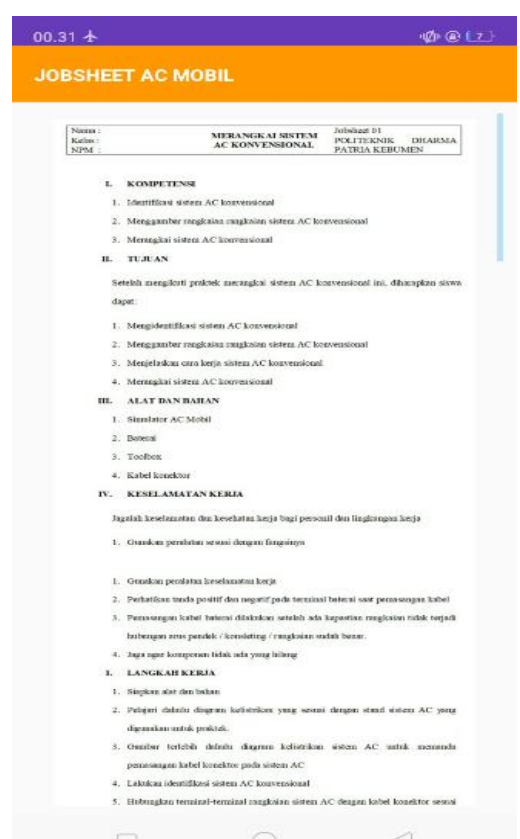

Gambar 7. Tampilan Soal Perawatan Sistem Air Conditioner

Pada layar jobsheet sistem air conditioner berisi berisis tentang data-data atau materi tentang perawatan pada air conditioner. Layar jobsheet sistem air conditioner disajikan pada Gambar 8.

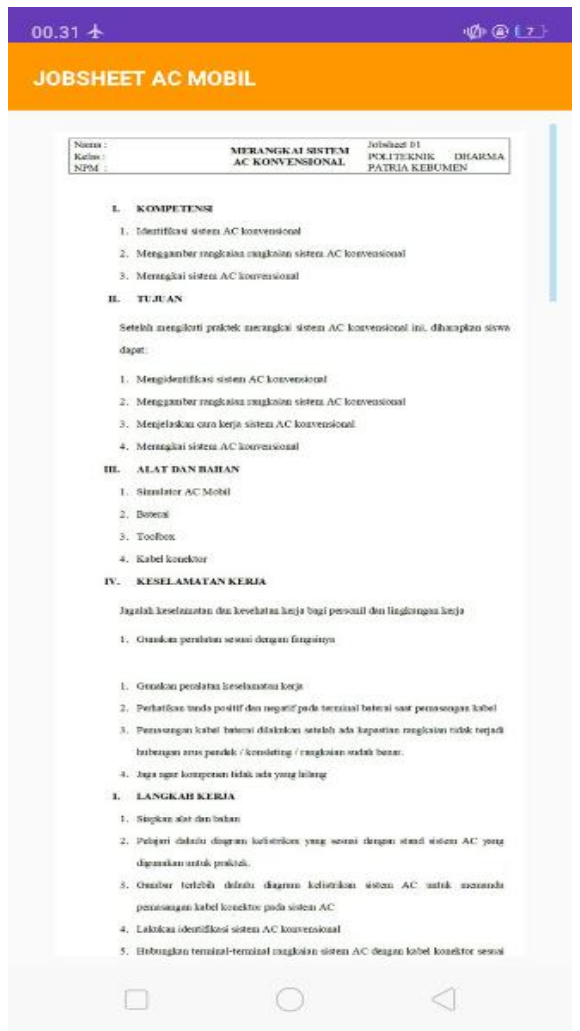

Gambar 8. Tampilan Jobsheet Perawatan Sistem Air Conditioner 


\subsection{Validasi Pengembangan Media Pembelajaran Berbasis Android Sketchware}

Media pembelajaran dibuat dan dikembangkan sesuai dengan Rencana Pembelajaran Semester (RPS) pada mata kuliah sistem air conditioner. Pengembangan media pembelajaran divalidasi oleh ahli materi dan media sebelum dilakukan uji coba. Data hasil uji coba produk media pembelajaran adalah: a) Kelayakan produk oleh ahli materi dalam kategori sangat layak dengan skor rerata 77 pada skor rerata maksimal 86. b) Kelayakan oleh ahli media dalam kategori sangat layak dengan skor rerata 75 pada skor rerata maksimal sebesar 86 .

\subsection{Efektivitas Pengembangan Media Pembelajaran Berbasis Android Sketchware}

Pengambilan data tes mahasiswa dilakukan pada kelas kontrol dan kelas eksperimen. Pada kelas eksperimen diterapan penggunaan pengembangan media pembelajaran dan kelas kontrol tanpa menggunakan pengembangan media pembelajaran. Dengan perhitungan rata-rata dan perhitungan $t$-test dapat dilihat pada Tabel 1.

Tabel 1. Deskripsi hasil analisis data

\begin{tabular}{llll}
\hline No & Kelompok & Rata-Rata & Nilai P value sig (2- tailed \\
\hline $\mathbf{1}$ & Eksperimen & 23 & \multirow{2}{*}{0,000} \\
$\mathbf{2}$ & Kontrol & 14 & \\
\hline
\end{tabular}

Berdasarkan deskripsi hasil analisis data, ada efektivitas dalam mengembangkan media pembelajaran berbasis android sketchware untuk meningkatkan kompetensi sistem air conditioner di Politeknik Dharma Patria ditinjau dari hasil belajar sitem air conditioner.

\section{KESIMPULAN}

Pada penelitian ini menghasilkan produk berupa pengembangan media pembelajaran berbasis android sketchware untuk meningkatkan kompetensi sistem air conditioner. Pengembangan media pembelajaran antara lain: sejarah, komponen, kelistrikan, cara kerja, perawatan, soal, dan jobsheet sistem air conditioner sehingga efisien dan efektif digunakan sebagai media pembelajaran di Politeknik Dharma Patria. Pengembangan media pembelajaran berbasis android sketchware untuk meningkatkan kompetensi sistem air conditioner mendapatkan kriteria sangat layak oleh ahli materi dan media yang. Kemudian uji coba produk akhir dilakukan pada mahasiswa prodi teknik mesin otomotif dan mendapatkan hasil adanya efektivitas dalam mengembangkan media pembelajaran berbasis android sketchware untuk meningkatkan kompetensi sistem air conditioner di Politeknik Dharma Patria. 


\section{REFERENSI}

[1] Astuti, I.A.D., Dasmo, dan Sumarni, R. Pengembangan Media Pembelajaran Berbasis Androis Dengan Menggunakan Aplikasi Appypie Di SMK Bima Mandiri Depok. Jurnal Pengabdian Masyarakat UNIMED, Vol 24, No.2 2018, pp 695-701

[2] Wulandari, A. 2018. Pengembangan Media Pembelajaran Berbasis Android Pada Dasar-Dasar Algoritma Dan Pemrograman Untuk Siswa Kelas X SMK Nasional Berbah. Skripsi. Pendidikan Teknik Informatika. UNY. Yogyakarta

[3] Amirullah, G dan Hardinata, R. Pengembangan Mobile Learning Bagi Pembelajaran. Jurnal Kesejahteraan Keluarga dan Pendidikan. Vol.04 No.02. 2017, pp 97-101

[4] Kuswanto, J \& Radiansah, F. Media Pembelajaran Berbasis Android Pada Mata Pelajaran Sistem Operasi Jaringan Kelas XI. Jurnal Media Infotama. Vol. 14, No. 1, 2018, pp 15-20

[5] Perdana, P.K.W. 2020. Pengembangan Media Pembelajaran Berbasis Aplikasi Android Berupa Buku Saku Digital Pada Materi Sistem Saraf Manusia Kelas XI SMA. Skripsi. Pendidikan Matematika dan Ilmu Pengetahuan Alam. Universitas Sanata Dharma. Yogyakarta

[6] Sari,V.M, Supriyadi,E dan Surwi,F. Pengembangan Multimedia Berbasis Android Untuk Kompetensi Dasar Pengukuran Listrik Di Sekolah Menengah Kejuruan. Jurnal Edukasi Elektro, Vol. 3, No. 2, 2019, pp 121-127

[7] Irawan, H. 2019. Aplikasi Mobile Learning Menggunakan Sketchware pada SMK Negeri 2 Pangkalpinang Berbasis Android. Skripsi. Teknik Informatika. Sekolah Tinggi Manajemen Informatikan dan Manajemen. Pangkalpinang

[8] Zega, A. 2019. Pengembangan Media Pembelajaran Menggunakan Sketchware Untuk Mengetahui Kemampuan Literasi Visual Pada Materi Good Manufacturing Practices Di Smk Pertanian Pembangunan Negeri Lembang. Skripsi. Program Studi Pendidikan Teknologi Agroindustri. Universitas Pendidikan Indonesia. Bandung

[9] Handoko. 2007. Merawat dan Memperbaiki AC Mobil. Jakarta: PT. Kawan Pustaka

[10] Daryanto. 2010. Media Pembelajaran (Peranannya Sangat Penting dalam Mencapai Tujuan Pembelajaran). Yogyakarta: Gava Media 